\title{
Limitations of a coupled regional climate model in the reproduction of the observed Arctic sea-ice retreat
}

\author{
W. Dorn, K. Dethloff, and A. Rinke \\ Alfred Wegener Institute for Polar and Marine Research, Telegrafenberg A43, 14473 Potsdam, Germany \\ Correspondence to: W. Dorn (wolfgang.dorn@awi.de)
}

Received: 9 March 2012 - Published in The Cryosphere Discuss.: 27 March 2012

Revised: 13 July 2012 - Accepted: 14 August 2012 - Published: 14 September 2012

\begin{abstract}
The effects of internal model variability on the simulation of Arctic sea-ice extent and volume have been examined with the aid of a seven-member ensemble with a coupled regional climate model for the period 1948-2008. Beyond general weaknesses related to insufficient representation of feedback processes, it is found that the model's ability to reproduce observed summer sea-ice retreat depends mainly on two factors: the correct simulation of the atmospheric circulation during the summer months and the seaice volume at the beginning of the melting period. Since internal model variability shows its maximum during the summer months, the ability to reproduce the observed atmospheric summer circulation is limited. In addition, the atmospheric circulation during summer also significantly affects the sea-ice volume over the years leading to a limited ability to start with reasonable sea-ice volume into the melting period. Furthermore, the sea-ice volume pathway shows notable decadal variability that varies in amplitude among the ensemble members. The scatter is particularly large in periods when the ice volume increases, indicating limited skill in reproducing high-ice years.
\end{abstract}

\section{Introduction}

The Arctic has been subjected to a variety of changes in atmospheric, oceanic, and sea-ice conditions in recent years. The strongest and most evident climate change signal is the shrinking sea-ice cover: the decrease of its thickness and spatial extent since 1979 (e.g. Stroeve et al., 2006; Serreze et al., 2007). This sea-ice loss can be best explained by a combination of strong natural variability in the coupled atmosphereice-ocean system and increased radiative forcing due to ris- ing concentrations of atmospheric greenhouse gases as summarized by Serreze et al. (2007). The observed decline in sea-ice extent reflects a combination of thermodynamic and dynamic feedback processes, involving changes in surface air temperature, radiative fluxes, and oceanic heat transport as well as changes in the sea-ice circulation in response to winds and ocean currents.

It is quite obvious that the variety of processes and their interplay makes it difficult for coupled climate models to reproduce the observed sea-ice distribution and its trend, leading to large model deviations in the simulation of presentday Arctic sea ice (see e.g. Gerdes and Köberle, 2007; Holland et al., 2010). Even though all coupled climate models involved in the Intergovernmental Panel on Climate Change Fourth Assessment Report (IPCC AR4) showed declining Arctic sea ice over the last $50 \mathrm{yr}$, only very few individual model simulations showed trends comparable to recent observations (Stroeve et al., 2007). This fact demonstrates that there is still large uncertainty about the Arctic's actual path into the future.

Coupled climate models are traditionally a composite from stand-alone models for the subsystems (primarily atmosphere and ocean-sea ice models). In stand-alone models, however, feedback processes between the subsystems, such as the ice-albedo feedback, can be disregarded, often resulting in oversimplified descriptions of the underlying physics. As sea ice is highly sensitive to changes in atmospheric and oceanic forcings (Hunke, 2010), such "simplified physics" constitute general weaknesses for the performance of coupled model systems in which feedbacks play a central role. A basic limitation in reproducing the observed Arctic seaice retreat with coupled climate models can therefore be attributed to insufficient simulation of feedbacks between the 
model components. In recent years, there have already been some efforts to improve model parameterizations involved in feedback processes between atmosphere and sea ice (e.g. Pedersen et al., 2009; Dorn et al., 2009; Andreas et al., 2010a,b), but there is still need for further improvement.

A second limitation can be attributed to some kind of intrinsic random variability, arising mostly from model initializations with more or less arbitrary ocean and sea-ice states (see e.g. Sorteberg et al., 2005; Döscher et al., 2010). As a consequence, the response of Arctic sea ice to an externally forced climate change signal can vary strongly between different model realizations. It is therefore necessary to separate externally forced variations from the intrinsic internal variability by means of analysis of ensemble simulations.

In the present paper, regional Arctic climate model ensemble simulations will be analyzed. The model and the ensemble simulation setup will be described in Sect. 2. The regional model approach allows to distinguish between external variability, entering the Arctic from outside the model domain in terms of varying large-scale atmospheric circulation structures, and internal variability, emerging within the model due to nonlinear responses to the external forcing. The modeled sea-ice climatology and variability will be discussed in Sect. 3 followed by an analysis of the correlation between sea ice and atmospheric circulation patterns in Sect. 4 and two example cases in Sect. 5. The final section summarizes the results and adds conclusions.

The aim of the study is the identification of limitations in reproducing the observed Arctic sea-ice retreat having regard to unknown initial conditions for ocean and sea ice, internal variability of the atmospheric circulation, and general uncertainties due to insufficient description of Arctic climate processes.

\section{Description of model and simulations}

\subsection{The coupled regional climate model}

The coupled regional climate model HIRHAM-NAOSIM used in this study consists of the regional atmospheric climate model HIRHAM (Christensen et al., 1996; Dethloff et al., 1996) and the high-resolution version of the North Atlantic/Arctic Ocean sea-ice model NAOSIM (Karcher et al., 2003; Kauker et al., 2003). The two stand-alone models were designed for Arctic climate simulations and already successfully applied for a wide range of Arctic climate studies.

The atmosphere component HIRHAM was set up on an integration domain that covers the whole Arctic north of about $60^{\circ} \mathrm{N}$ at a horizontal resolution of $0.5^{\circ}$ (about $50 \mathrm{~km}$ ) on a rotated latitude-longitude grid with the North Pole on the geographical equator at $0^{\circ} \mathrm{E}$. In the vertical, the model has 19 unevenly spaced levels in hybrid sigma-pressure coordinates from the earth's surface up to a height of $10 \mathrm{hPa}$, with the lowest spacing in the lower troposphere.
The ocean-ice component NAOSIM is discretized on a rotated spherical grid, where the model equator corresponds to the geographical $30^{\circ} \mathrm{W} / 150^{\circ} \mathrm{E}$ meridian, with a horizontal resolution of $0.25^{\circ}$ (about $25 \mathrm{~km}$ ) and 30 unevenly spaced zcoordinate levels in the vertical. The southern model boundary of NAOSIM is approximately located at $50^{\circ} \mathrm{N}$ in the Atlantic. Here an open boundary condition has been implemented following the method of Stevens (1991), while all other boundaries, including the Bering Strait, are treated as closed walls. The open boundary condition allows for the outflow of tracers and the radiation of waves. At inflow points, as determined by the model, temperature and salinity are restored with a time constant of 180 days towards the Levitus climatology (Levitus and Boyer, 1994; Levitus et al., 1994).

The coupled HIRHAM-NAOSIM system was applied for the first time by Rinke et al. (2003) and subsequently by Dorn et al. (2007), who also gave a detailed description of the basic model setup. Over the last years, a few parameterizations in HIRHAM-NAOSIM were replaced by more sophisticated schemes. The aim was to improve the onset of the summer sea-ice melt season and the simulation of the two-stage snow-albedo/ice-albedo feedback which can be regarded as one of the crucial factors for the magnitude of ice melt during summer. It turned out that a harmonized combination of improved parameterizations for ice growth, ice albedo, and snow cover on sea ice results in a substantial improvement in the simulation of the summer minimum in ice concentration. The improved schemes were described in great detail by Dorn et al. (2009), who also documented the improved model performance with respect to the summer sea-ice retreat.

\subsection{Ensemble simulation setup}

An ensemble of 7 hindcast simulations for the period 19482008 were carried out using NCEP/NCAR reanalysis data (Kalnay et al., 1996) as HIRHAM's lateral boundary forcing as well as HIRHAM's lower and NAOSIM's upper boundary forcing outside the overlap area of the two model domains as described by Dorn et al. (2007). All ensemble members were equally started on 1 January 1948 and run through 31 December 2008, but the initial ocean and sea-ice fields were taken from different years of a preceding coupled spin-up run (runA to runF) or from the final state of one of the ensemble members (runG) as listed in Table 1. The coupled spinup run itself was initialized with ocean and sea-ice fields of 25 February 1949 from a pre-existing stand-alone simulation of NAOSIM.

Previous experiments with HIRHAM-NAOSIM showed that the model needs about $6-10$ yr to arrive at a quasistationary cyclic state of equilibrium in sea-ice volume (Dorn et al., 2007). This is why the ensemble members were initialized with restart fields taken after not less than $6 \mathrm{yr}$ of coupled simulation, assuming that sea ice and upper ocean are then sufficiently adjusted. The restart field initialization 
Table 1. List of ensemble simulations with HIRHAM-NAOSIM for the period 1948-2008.

\begin{tabular}{ll}
\hline Ensemble run & \multicolumn{1}{c}{ Initialization of the ocean and ice fields } \\
\hline runA & with state of 1 January 1955 from spin-up run \\
runB & with state of 1 January 1956 from spin-up run \\
runC & with state of 1 January 1957 from spin-up run \\
runD & with state of 1 January 1958 from spin-up run \\
runE & with state of 1 January 1959 from spin-up run \\
runF & with state of 1 January 1960 from spin-up run \\
runG & with state of 1 January 2009 from runF \\
\hline
\end{tabular}

applies only to NAOSIM; HIRHAM was always initialized with atmospheric fields of 1 January 1948, 00:00 UTC from the NCEP/NCAR reanalysis.

The method of creating an ensemble of model simulations differs from the usual procedure in which the initial fields are only slightly disturbed from one ensemble member to the other (e.g. Döscher et al., 2010). Differences between the ensemble members then arise solely due to nonlinear interactions within the coupled system in response to the disturbance. In the present study, the initial state is already different between the ensemble members, but can also be seen as a large disturbance or initial uncertainty, since it is quite unknown how the real state of the Arctic Ocean was in the late 1940s.

To give a rating of the differences in the initial state, Table 2 lists the initial sea-ice volume, sea-ice area, and sea-ice extent of the ensemble runs as well as the resulting mean seaice thickness. While the initial ice area and ice extent differ by up to 1 million $\mathrm{km}^{2}$ among the runs (relative difference of less than $10 \%$ ), the initial ice volume and the resulting ice thickness even show relative differences of $20 \%$ and $24 \%$, respectively.

Since runG was initialized with modeled fields referring to 1 January 2009 (from a presumed low-ice period), it should be noted that this run is indeed characterized by the lowest initial mean ice thickness, but at the same time also by the largest initial sea-ice area and extent of all runs, while the initial sea-ice volume is still within the range of the other runs.

\section{Sea-ice climatology and variability}

The focus in this section is the evaluation of the spatial distribution and temporal evolution of sea-ice in the ensemble simulations. Since all ensemble members show an almost identical spatial distribution of sea ice on the climatological average, substantiated by monthly pattern correlation coefficients between 0.995 and 1.0, only the ensemble mean is discussed in terms of the climatology representative for the model climate of all ensemble members.
Table 2. Initial sea-ice volume, sea-ice area, and sea-ice extent (area with at least $15 \%$ ice concentration) of the ensemble runs and the resulting mean sea-ice thickness (ice volume divided by ice area). All values apply to the model domain as shown in Fig. 1.

\begin{tabular}{rrrrr}
\hline & $\begin{array}{r}\text { Ice volume } \\
{\left[10^{3} \mathrm{~km}^{3}\right]}\end{array}$ & $\begin{array}{r}\text { Ice area } \\
{\left[10^{6} \mathrm{~km}^{2}\right]}\end{array}$ & $\begin{array}{r}\text { Ice extent } \\
{\left[10^{6} \mathrm{~km}^{2}\right]}\end{array}$ & $\begin{array}{r}\text { Mean ice } \\
\text { thickness }[\mathrm{m}]\end{array}$ \\
\hline runA & 17.08 & 10.00 & 10.84 & 1.71 \\
runB & 17.61 & 10.52 & 11.30 & 1.67 \\
runC & 16.09 & 10.68 & 11.66 & 1.51 \\
runD & 16.86 & 10.69 & 11.54 & 1.58 \\
runE & 15.83 & 10.63 & 11.46 & 1.49 \\
runF & 14.41 & 10.35 & 11.28 & 1.39 \\
runG & 14.54 & 10.80 & 11.89 & 1.35 \\
\hline
\end{tabular}

\subsection{Ice thickness climatology}

The ensemble mean ice thickness climatology for March and September of the period 1948-2008 is shown in Fig. 1. In March, the thickest ice with more than $3 \mathrm{~m}$ on average appears north of the Canadian Arctic Archipelago. Most of the Arctic Ocean is covered with 2-3 m thick ice in March, and thinner ice appears along the Eurasian side of the Arctic Ocean.

In September, the ice thickness pattern is similar to that in March, but the ice is generally thinner (in most cases between $0.5-1 \mathrm{~m}$ ). More than $2 \mathrm{~m}$ thick ice now only occurs north of the Canadian Arctic Archipelago. The Baffin Bay and the Kara and Laptev Seas are only partly covered with ice in September, leading to a mean thickness well below $0.5 \mathrm{~m}$ in these regions. Both in March and in September, the differences between the ensemble mean and the ensemble members with the lowest/greatest mean ice thickness (runC/runG) only add up to a few centimeters (less than $8 \mathrm{~cm}$ on average).

The modeled spatial distribution of regions with thin and thick ice is in qualitative agreement with ice thickness climatologies derived from observations (e.g. Bourke and Garrett, 1987). However, the model produces on average thinner ice as compared with these climatologies. More recent estimates of ice thickness from ICESat campaigns between 2003 and 2008 (Kwok et al., 2009) reveal somewhat better agreement with the simulated ice thicknesses, when disregarding regional details. An extensive quantitative evaluation of the modeled ice thicknesses is beyond the scope of this paper and actually not possible, because ice thickness measurements are unavailable for the whole Arctic Ocean over the period 1948-2008.

\subsection{Ice extent climatology}

The mean ice extent, shown in Fig. 1 as white lines (model) and orange lines (reanalysis), is overestimated by the model in the Greenland Sea, the Barents Sea, and, in particular, in the Labrador Sea in March. The overestimate of sea ice in 

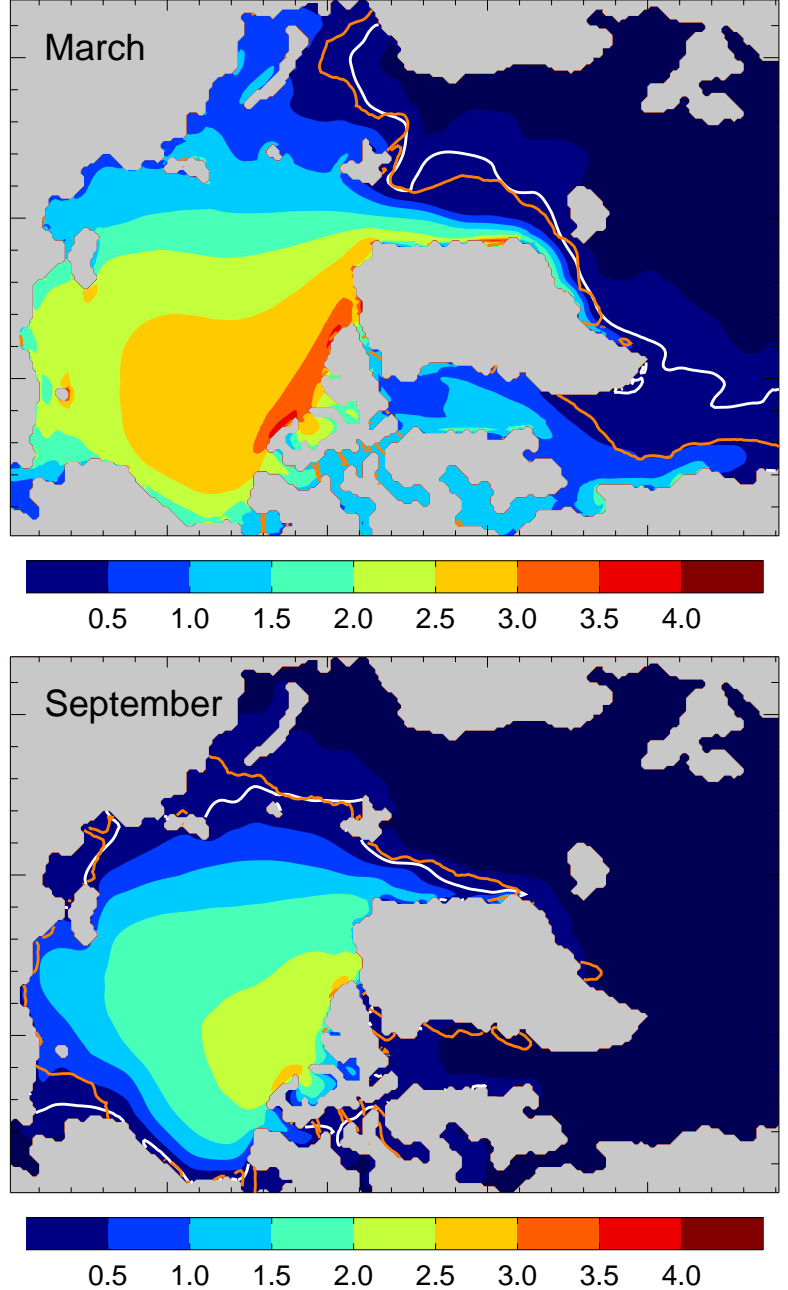

Fig. 1. Ensemble mean ice thickness climatology of the period 1948-2008 (in meters) for March (top) and September (bottom). The white lines show the climatological ice extent of the ensemble mean and the orange lines the climatological ice extent from NCEP/NCAR reanalysis data. Land areas are shown in gray, and the always completely ice-free ocean is shown in black.

the Labrador Sea can be regarded as a specific shortcoming of the coupled model, since it appears in all winters and all ensemble members. The reason behind this model bias is unknown. It is likely to result from an imbalanced interaction between HIRHAM and NAOSIM which amplifies in the course of the winter due to a positive feedback. This conjecture is supported by the fact that NAOSIM does not show such a bias in stand-alone mode when NCEP/NCAR reanalysis data are used as atmospheric forcing (see Kauker et al., 2003).

In contrast to March, the modeled mean ice extent agrees rather well with the reanalysis in September, except for the northern Kara Sea, where the model underestimates the ice extent, and the Chukchi Sea, where the model overestimates the ice extent on the climatological average. The latter might be a result of the closed Bering Strait in the model, whereby the inflow of warmer waters from the Bering Sea into the Chukchi Sea is disabled, leading to later onset and reduced melting in this region (see e.g. Woodgate et al., 2010).

\subsection{Temporal variability in ice volume}

Despite almost identical climatological patterns of ice thickness and extent, there are large deviations in the temporal trend of these variables among the ensemble members.

Figure 2 shows the temporal evolution of the ice volume in March and September for the ensemble mean and the two most extreme ensemble members (runC and runG). Overall, there is large agreement between the ice volume trends in March and September. In most cases, major changes in ice volume appear first in September followed by corresponding changes in March, indicating that the strength of summertime ice loss plays a dominant role in the variability of the ice volume. The mean correlation coefficient $(r)$ between the time series of the ice volume in September and in the following March is 0.96 , compared to $r=0.90$ between the ice volume in March and in the following September. Both correlations are statistically significant. The consequence is that thick ice tends to remain thicker for some years and vice versa. The year-to-year variability in ice volume is therefore relatively low.

In contrast to the low interannual variability, all ensemble members show pronounced multi-decadal variability in ice volume. After a period of ice loss in the early 1950s, there is a period with low ice volume in the late 1950s and an increase in ice volume from 1960 to about 1984. Afterwards the ice volume remains high for some years, followed by a rapid decrease from approximately 2002 onwards. The increase in ice volume in the early 1960s is likely to be triggered by large-scale atmospheric circulation changes, especially since it also appeared in stand-alone NAOSIM simulations driven by NCEP/NCAR reanalysis data (see Köberle and Gerdes, 2003, their Fig. 4) and other ocean-ice models (Holloway and Sou, 2002; Rothrock and Zhang, 2005).

It is conspicuous that there is a large scatter among the ensemble members in periods when the ice volume increases or stays in a high state. The two-standard deviation range of the ensemble spans up to $5000 \mathrm{~km}^{3}$, which is partly more than $50 \%$ of the mean ice volume in September. In periods when the ice volume decreases, the scatter among the ensemble members is just half as large, indicating the dominant influence of the external forcing as driver for perennial ice loss.

To give a quantitative estimate of the relative importance of the nonlinear interplay of internal processes and the external forcing for the overall variability of the ice volume, the ratio of the mean standard deviation of the ensemble member time series, as indication of the mean external variability, to the time average of the annual ensemble standard deviations, as indication of the mean internal variability, was calculated in a similar way as the signal/noise ratio by 

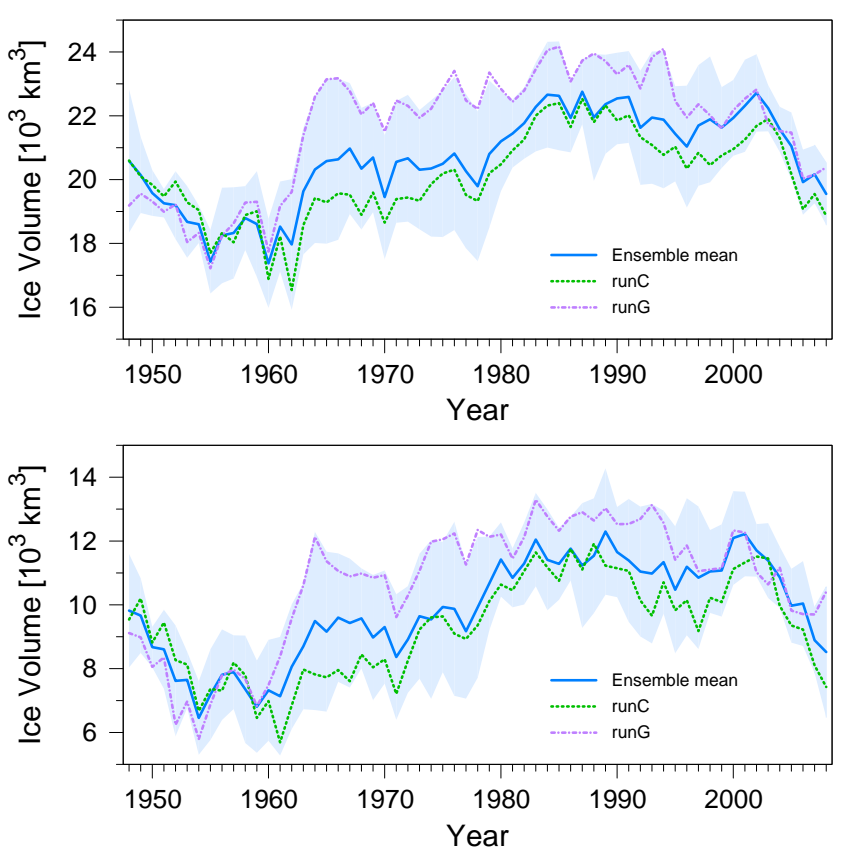

Fig. 2. Temporal trend of sea-ice volume within the model domain in March (top) and September (bottom) from 1948 to 2008. The solid blue lines represent the ensemble mean and the blue shaded areas the two-standard deviation range of the ensemble. The dashed green lines represent runC and the dash-dotted purple lines runG.

Döscher et al. (2010), except for a different definition of external variability. This ratio is hereinafter simply referred to as standard deviation ratio (SDR). Values of SDR larger than one indicate a stronger influence of the large-scale external forcing versus the internal variability. The overall dominating influence of the large-scale external forcing on the variability in ice volume is reflected in the values $\mathrm{SDR}=2.10$ for March and SDR $=2.21$ for September. The internal processes play a secondary but non-negligible role in the ice volume variability.

The strongest deviation from the ensemble mean shows runG, which was initialized with the relatively thin ice state of 1 January 2009. Despite the existence of a thin ice cover at model start, runG shows by far the strongest increase in ice volume in the early 1960s and the highest ice volume of all ensemble members in the following $30 \mathrm{yr}$ (see Fig. 2). This finding is in contradiction to the hypothesis that the Arctic sea ice system (at least in the model) might already have passed a tipping point as of which the sea ice will inevitably continue to retreat due to positive feedbacks (see e.g. Lindsay and Zhang, 2005). Favorable large-scale atmospheric conditions for a net increase of sea ice, as they obviously occurred in the 1960s and 1970s, are able to recover a state with higher ice volume within a few years. The unlikelihood of the existence of a tipping point is consistent with other studies (Eisenman and Wettlaufer, 2009; Notz, 2009; Tietsche et al., 2011).
It has been demonstrated by Schröder and Connolley (2007) as well as Tietsche et al. (2011) that even total removal of Arctic sea ice will almost completely recover back to the appropriate climate state within a few years. This finding is in accordance with previous HIRHAM-NAOSIM experiments (Dorn et al., 2007) and basically means that uncertainties in the initial sea-ice conditions are unimportant for climate modeling on decadal or longer time scales (Schröder and Connolley, 2007). The large ensemble scatter can therefore be interpreted as a result of the nonlinear interplay of internal atmospheric, oceanic, and sea-ice processes in response to the initial uncertainty. Specific variations in the initial state should be a matter of no particular importance.

The large deviation of runG from the other ensemble members, with ice volumes often close to the edge of the twostandard deviation range of the ensemble mean, indicates the existence of a bifurcation in terms of the sea-ice volume pathway, which appears in the model in the year 1960. Even though only one ensemble member takes the high-ice path, it would agree better with the path of the real climate system, given that observational data suggest that the Arctic ice cover was thicker in the 1960s and 1970s than in the 1990s (e.g. Rothrock et al., 1999; Wadhams and Davis, 2000; Kwok and Rothrock, 2009). The model's thin ice cover in the 1950s, indicated by low ice volume, is not supported by observations and could be due to a widespread warm bias over Eurasia in the NCEP/NCAR reanalysis in the 1950s, as noted by Grant et al. (2009). However, knowledge of the real ice thicknesses is severely limited due to the lack of observations from that time period.

\subsection{Temporal variability in ice extent}

The temporal trend of the ice extent in March and September is shown in Fig. 3 for the ensemble mean, the NCEP/NCAR reanalysis data, and SSM/I satellite-derived data (Comiso, 1990, updated 2009). In contrast to the ice volumes, the ice extents in March and September show a weak correlation (correlation coefficients between 0.15 and 0.5). However, there is a significant correlation between the ice volume in March and the ice extent in September $(r=0.65$ between March ice volume and September ice extent in the same year and $r=0.76$ between September ice extent and March ice volume in the following year).

In March, the model systematically overestimates the ice extent due to the overestimate of sea ice in the Labrador Sea as noted before. Also, the model shows strong interannual variability going far beyond the year-to-year variability of the observations. The mean standard deviation of the ensemble member time series is $0.53 \times 10^{6} \mathrm{~km}^{2}$ versus $0.29 \times 10^{6} \mathrm{~km}^{2}$ in the NCEP/NCAR reanalysis data. The reason for this behavior is that the position of the ice edge is not so heavily constrained in the model as in the observations. However, the scatter among the ensemble members is generally low in March, indicated by a value of SDR $=3.08$. This means that 

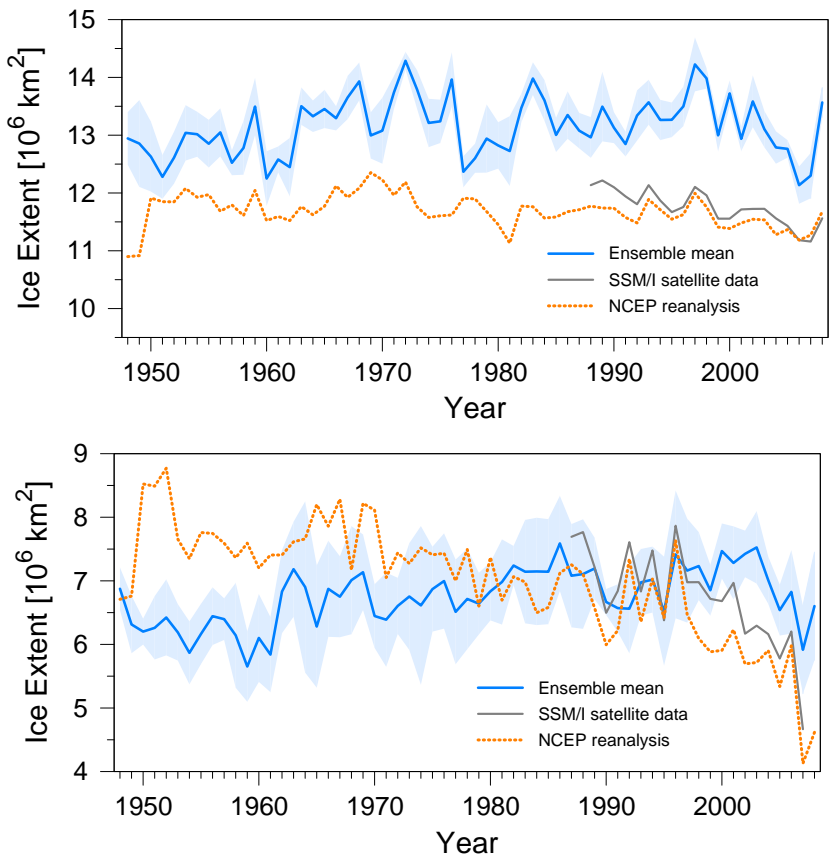

Fig. 3. Temporal trend of sea-ice extent within the model domain in March (top) and September (bottom) from 1948 to 2008. The solid blue lines represent the ensemble mean and the blue shaded areas the two-standard deviation range of the ensemble. The solid gray green lines represent SSM/I satellite-derived ice extent and the dashed orange lines ice extent from NCEP/NCAR reanalysis data. SSM/I and NCEP data were interpolated onto the model grid.

most of the variability in winter ice extent is caused by the large-scale atmospheric forcing. Since the model responds consistently but more strongly to this forcing than the observations, it indicates a systematic model error.

In September, the observational data show a pronounced downward trend in ice extent over the period from 1948 to 2008 which is not reproduced by the model. All ensemble members show lower ice extent during the 1950s, an increase in September ice extent between 1961 and 1963, associated with the increase in ice volume, but still lower ice extent until the late 1970 s, and different year-to-year variability until the late 1980s. In part, there is agreement in the 1990s, especially with the SSM/I data, but the strong decrease in September ice extent observed during the last $10 \mathrm{yr}$ is much weaker in the model, even though the 2007 minimum is also present in all ensemble members. In comparison to the ice extent in March, the scatter among the ensemble members is much greater $(\mathrm{SDR}=1.79)$, indicating that internal variability plays a more prominent role in summer.

It should be noted that in some years the two observational datasets clearly differ in September sea-ice extent, although SSM/I sea-ice data were incorporated into the NCEP/NCAR reanalysis product (Kalnay et al., 1996). The discrepancy can partly be attributed to different algorithms to retrieve seaice concentration from microwave emission, different spa- tial resolution of the datasets, and different methods of the interpolation onto the model grid. A third sea-ice dataset (HadISST1; Rayner et al., 2003) offers a third solution (not shown), but it reveals better agreement with the SSM/I data from 1997 onwards. For this reason, SSM/I data are used as sea-ice observations for the example cases in Sect. 5.

\subsection{Seasonal cycle of the variability}

The seasonal cycle of the domain-averaged SDR (as introduced in Sect. 3.3 as a measure for external versus internal variability) is shown in Fig. 4 for a sample of atmospheric and sea-ice variables. The SDRs of the ice thicknesses and concentrations are consistent with those of ice volume and extent as discussed in the previous sections.

While the ice concentration (as well as the ice extent) show a pronounced seasonal cycle of the SDRs with maximum in February and March and minimum in August and September, the SDRs of ice thickness (as well as of ice volume) feature only marginal seasonal variations and generally lower values than all other variables. This might be an indication of an internal memory effect that hampers any quick response to external fluctuations. The existence of an internal memory effect of the sea-ice pack as a whole is supported by ensemble mean lag-1 (lag-2) autocorrelation coefficients of September sea-ice volume of 0.90 (0.81). Almost the same mean lag-1 and lag-2 autocorrelation coefficients are found for March sea-ice volume. Nevertheless, the external variability of the ensemble members is still greater than the mean internal variability of the ensemble, which find expression in SDRs greater than one. This indicates in turn that the general pathway of the ice volume is finally a response to external changes on interannual to decadal time scales.

Compared to the sea-ice variables, the SDR of the atmospheric variables is generally higher and the seasonal cycle of the SDRs, especially of 500-hPa geopotential height and mean sea level pressure, is more pronounced with values in winter more than twice as high as in summer. Particularly during the winter months, the ensemble standard deviations are small in comparison with the temporal variability of the large-scale atmospheric circulation from one year to the other. This characteristic changes in April when solar radiation begins to take full effect. During the polar day, especially from June to September, local processes within the Arctic climate system increase in their importance for the variability as large-scale processes decrease.

As the atmospheric circulation in winter is much stronger constrained by the external boundary forcing, the model has higher degree of freedom to develop internal circulation structures in summer. The increasing internal atmospheric variability from May to September (not explicitly shown) might originate from higher effectiveness of inner-Arctic feedback processes when solar radiation is available, for instance due to lower static stability of the atmospheric boundary layer (see e.g. Devasthale et al., 2010) and increased 


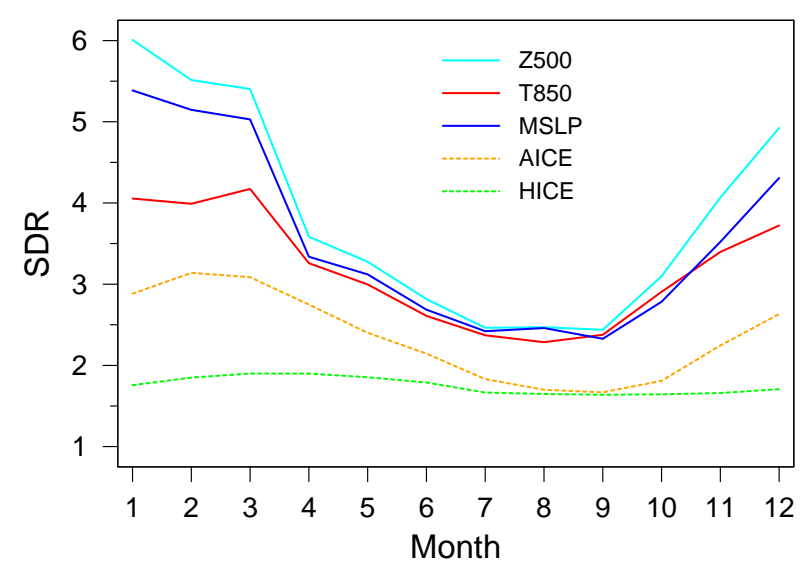

Fig. 4. Seasonal cycle of the standard deviation ratio (SDR), defined as ratio of the domain-averaged mean standard deviation of the ensemble member time series to the domain and time average of the ensemble standard deviations, for monthly means of 500hPa geopotential height (Z500; cyan), 850-hPa temperature (T850; red), mean sea level pressure (MSLP; blue), sea-ice concentration (AICE; orange), and sea-ice thickness (HICE; green). Sea-ice concentration and thickness refer to the NAOSIM domain without land areas, while all other variables refer to the HIRHAM domain without a 10-grid-point-wide boundary zone where internal variability of the ensemble is negligible.

potential for baroclinic instability and cyclogenesis over the Arctic Ocean (see e.g. Serreze and Barrett, 2008). It is hypothesized that the more prominent role of internal variability in late summer sea-ice extent and concentration is, to a great extent, affected by the internal variability of the atmospheric circulation a few months earlier due to modulations of the ice drift and the ice melt rate.

\section{Correlation between sea ice and atmospheric circulation patterns}

To investigate the role of the atmospheric circulation in seaice changes, correlation coefficients between time series of atmospheric variables at each grid point on the one hand and time series of ice extent and ice volume changes on the other hand have been calculated. Figure 5 shows correlation maps between mean sea level pressure, 500-hPa geopotential height, and 850-hPa temperature in summer (June to August) and ice extent and ice volume changes from May to September from NCEP/NCAR reanalysis data and the ensemble mean. The ensemble mean is here representative for all ensemble members.

Linear trends in the time series of the ice extent and ice volume changes have been subtracted out to avoid spurious correlations due to the memory effect of the sea-ice pack. Further, decrease of sea ice from May to September, which is the usual case, has been defined as negative change. This means that positive correlations appear for high values of the atmospheric variable and low sea-ice decrease and vice versa.

The significant negative correlations that appear over most of the Arctic Ocean in all maps of Fig. 5 indicate that high pressure at sea level, high geopotential at $500 \mathrm{hPa}$, and high temperatures at $850 \mathrm{hPa}$ over the Arctic Ocean during the summer months are accompanied by strong sea-ice decrease, both strong retreat of the sea-ice cover and strong loss of seaice mass in total. The similarity of the correlations for the three atmospheric variables further indicates that strong seaice loss is either associated with higher frequency of occurrence of high-reaching warm anticyclones or lower cyclone frequency over the Arctic Ocean.

Even though there are differences between the model results and the NCEP/NCAR reanalysis data with respect to the geographic location of significant negative correlation coefficients, the importance of cyclonic or anticyclonic atmospheric circulation in summer for the summer sea-ice decline is a common feature. Considering that corresponding analyses for the winter and spring circulation have resulted in no consistently significant correlation with sea-ice changes in both summer and winter, the atmospheric circulation in summer must consequently also play an important role in yearto-year changes of sea ice.

Figure 6 shows corresponding correlation maps between mean sea level pressure, 500-hPa geopotential height, and 850-hPa temperature in summer (June to August) and yearto-year changes of September sea-ice extent and volume from NCEP/NCAR reanalysis data and the ensemble mean. There is qualitative agreement between the correlation maps relating to summer sea-ice changes and year-to-year changes. Warm anticyclonic conditions over the Arctic Ocean during summer mostly result in reduced September sea-ice extent and volume compared to the previous year. In contrast, cold cyclonic conditions over the Arctic during summer promote an increase in September sea-ice extent and volume compared to the previous year.

Despite the substantial similarity of the correlation maps in the model and NCEP/NCAR reanalysis data, there is a significant difference in the gradients of the correlation fields between mean sea level pressure and sea-ice extent. The NCEP/NCAR reanalysis data show a gradient in the correlation fields indicating sea-ice change-related differences in the pressure gradient and associated winds from the Pacific region to the East Siberian and Laptev Seas and from the Arctic Ocean to the Nordic Seas. In contrast, the model shows strongly negative correlations over most of the Arctic Ocean with only weak gradients over most sea areas. Because winds are the primary driver of sea-ice drift, the atmospheric pressure gradient impacts sea-ice motion and export (Perovich and Richter-Menge, 2009). The importance of atmospherically driven sea-ice drift for sea-ice changes might therefore be lower in the model than in reality.

It should be noted that the correlation coefficients very rarely exceed a value of 0.6 (in the model) and 0.4 (in the 

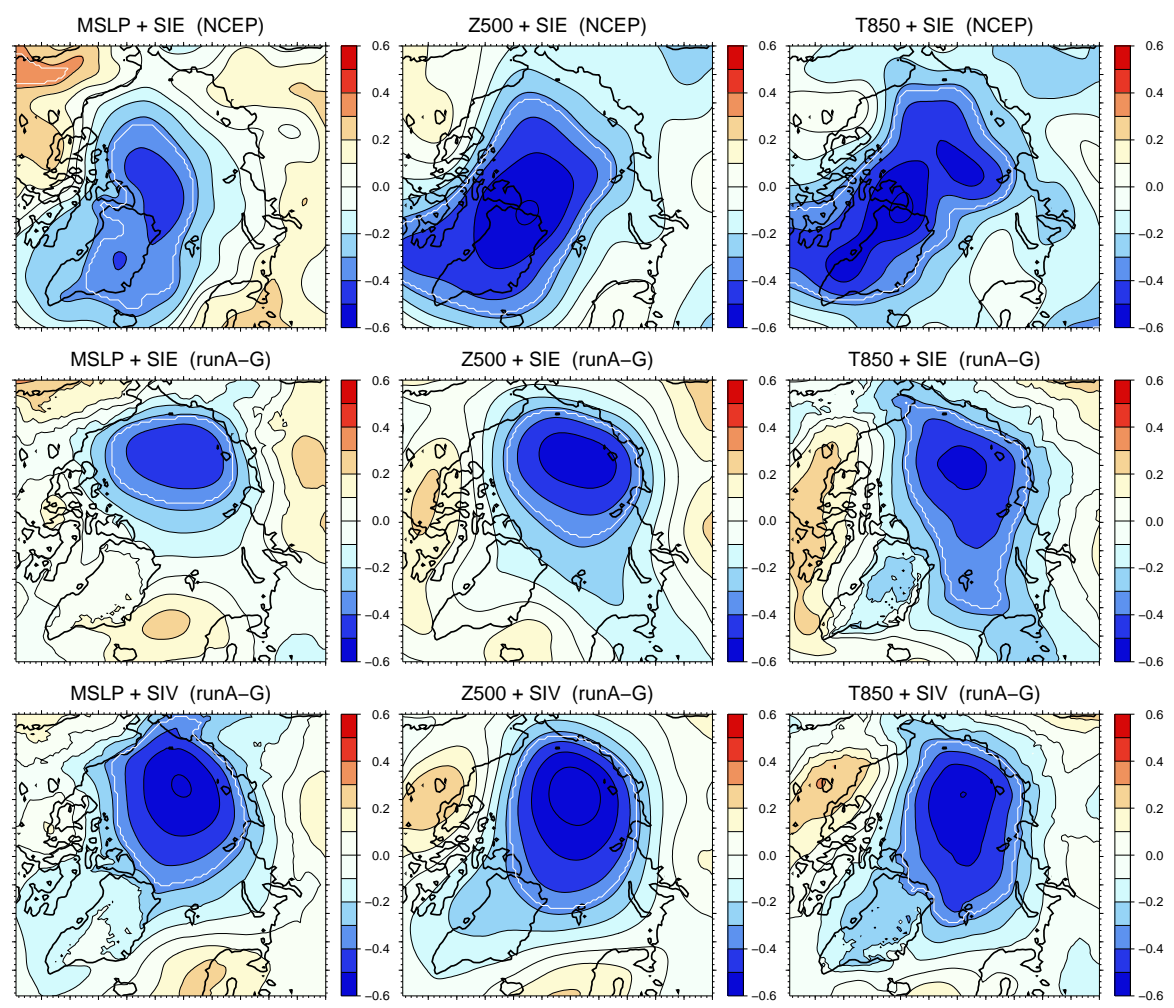

Fig. 5. Spatial patterns of the correlation coefficients between the time series of mean sea level pressure (MSLP), 500-hPa geopotential height (Z500), and 850-hPa temperature (T850) in summer (June to August), and sea-ice extent (SIE) and sea-ice volume (SIV) changes from May to September for the period 1948-2008 from NCEP/NCAR reanalysis data (NCEP; only SIE available) and the ensemble mean (runA-G). The white lines delimit the $99 \%$ significance level. The time series of the ice extent and ice volume changes have been detrended.

NCEP data), respectively. The explained variance of the seaice changes by the atmospheric circulation in summer is therefore relatively low $(<36 \%)$. In some cases, cyclonic atmospheric circulation during the summer months has also resulted in low sea-ice extent, as for instance in 2002 (see Serreze et al., 2003). Serreze et al. (2003) explain the 2002 minimum with poleward ice advection due to anomalous warm southerly winds in spring as well as ice divergence and enhanced ice loss due to cyclonic wind stress and high temperatures over the Arctic Ocean in summer. However, the usual case is that low September sea-ice extent is associated with anticyclonic atmospheric circulation anomalies (Ogi and Wallace, 2007), which agrees with the presented correlation analysis.

Statistically significant evidence that the atmospheric circulation in summer is influenced, in turn, by the sea-ice conditions in winter or spring has not been found. This is in particular of importance since the causes for the higher internal model variability during the summer months can not definitely be attributed to different sea-ice conditions.

\section{Example cases}

To provide deeper insight into the variations of the ensemble members during summer and potential reasons for the deviations from the observations, two example cases are discussed in this section: the summer 1995 and the summer 2007. The former was chosen because the September ice extent of the ensemble mean agrees well with SSM/I and NCEP data in spite of large scatter among the ensemble members (see Fig. 3). The summer 2007 was chosen because all ensemble members show the lowest values of September ice extent for the last three decades, but still significantly higher values than observed.

\subsection{Summer 1995}

September 1995 was characterized by relatively low ice extent in the Arctic. Most of the Kara, Laptev and East Siberian Seas were ice free at the end of the summer (see Fig. 7). From all of the ensemble members, runB shows the best agreement with the observed ice extent (pattern correlation coefficient of 0.91 between simulated and observed ice concentration). The worst agreement appears in runA (pattern correlation coefficient of 0.81 ). The other ensemble members lie in between, 


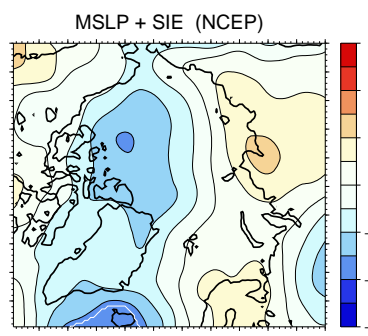

$M S L P+S I E($ runA-G)

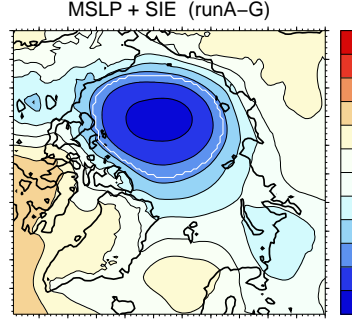

$\mathrm{MSLP}+$ SIV (runA-G)

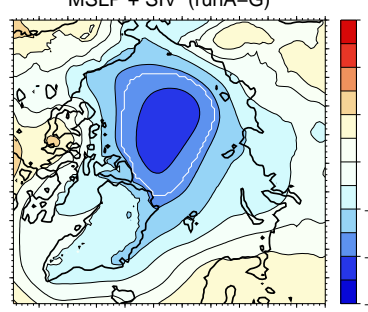

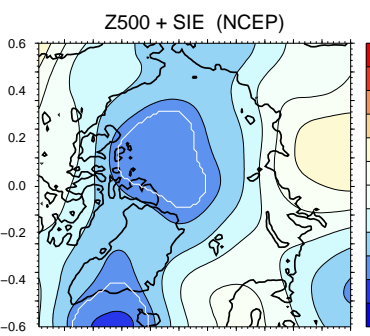

$\mathrm{Z} 500+\mathrm{SIE}$ (runA-G)

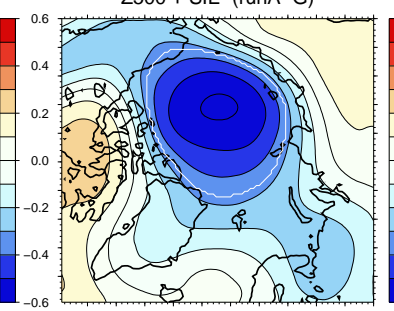

$\mathrm{Z} 500+\operatorname{SIV}$ (runA-G)

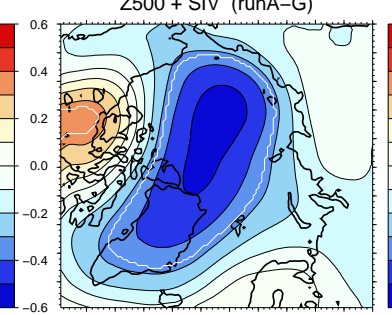

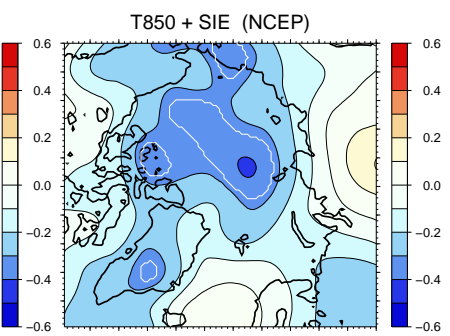

T850 + SIE (runA-G)

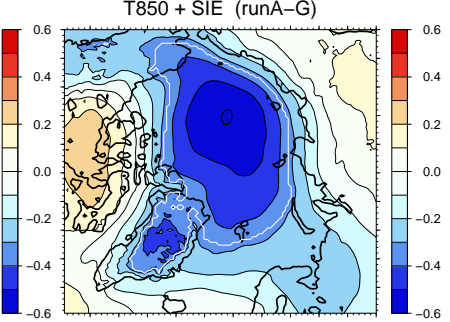

T850 + SIV (runA-G)

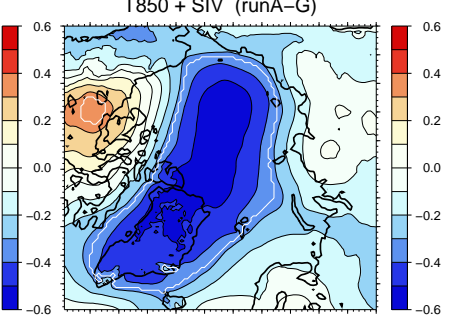

Fig. 6. As in Fig. 5, but for year-to-year changes of September sea-ice extent and volume for the period 1949-2008.

albeit runC and runF show almost equally high pattern correlation coefficients as runB ( 0.90 in either case).

It is obvious that runA and runB also differ widely in the simulated ice thickness distribution. While runB shows the more usual pattern with thick ice north of Greenland and the Canadian Arctic Archipelago, indicating a strong Transpolar Drift Stream (TDS), runA shows a more polar symmetric ice thickness distribution, which is characteristic for generally weaker ice motion, particularly weaker TDS. Given that the sea-ice motion is strongly affected by the atmospheric winds (Thorndike and Colony, 1982), the mean sea level pressure pattern of runA must be biased as well.

Figure 8 shows the mean sea level pressure in summer 1995 (June to August) from the 7 ensemble members and NCEP/NCAR reanalysis data. The reanalysis shows high pressure over the Beaufort Sea and low pressure over the Labrador Sea and over the extended region from Siberia across the Kara and Barents Seas to Svalbard, a sea level pressure pattern referred to as the positive Arctic Dipole Anomaly (DA) pattern (Wang et al., 2009). The positive DA pattern implies strong geostrophic winds from the Laptev Sea towards the Fram Strait and, taking account of compensating effects of Ekman spirals in atmosphere and ocean (see Thorndike and Colony, 1982), leads to an accumulation of sea ice north of Greenland and an outflow of sea ice from the Arctic Ocean through the Fram Strait into the northern
Atlantic. A large part of the sea-ice retreat in summer 1995 may be attributed to atmospherically driven sea-ice drift as discussed by Ogi et al. (2008).

Similar atmospheric circulation patterns with similarly strong geostrophic winds as in the reanalysis are only present in runB, runC, and runF. While runD and runE overestimate the high pressure area, runA and runG show different circulation patterns over the Arctic Ocean. The highest pattern correlation coefficients between simulated and observed mean sea level pressure appear in runB (0.81), runC (0.79), and runF (0.78), while runA shows the lowest pattern correlation coefficient (0.57) analogously to the lowest correlation in ice concentration.

The ensemble members, which rather failed in reproducing the observed mean sea level pressure pattern from June to August, also failed in reproducing the observed September sea-ice extent. A realistic simulation of the atmospheric circulation during summer can therefore be regarded as a basic prerequisite for a realistic simulation of the ice extent at the end of the summer.

\subsection{Summer 2007}

September 2007 was the month with the lowest sea-ice extent ever observed in the Arctic. A number of studies have been conducted to explain the potential causes for this anomalous ice retreat (Comiso et al., 2008; Stroeve et al., 2008; Kay 

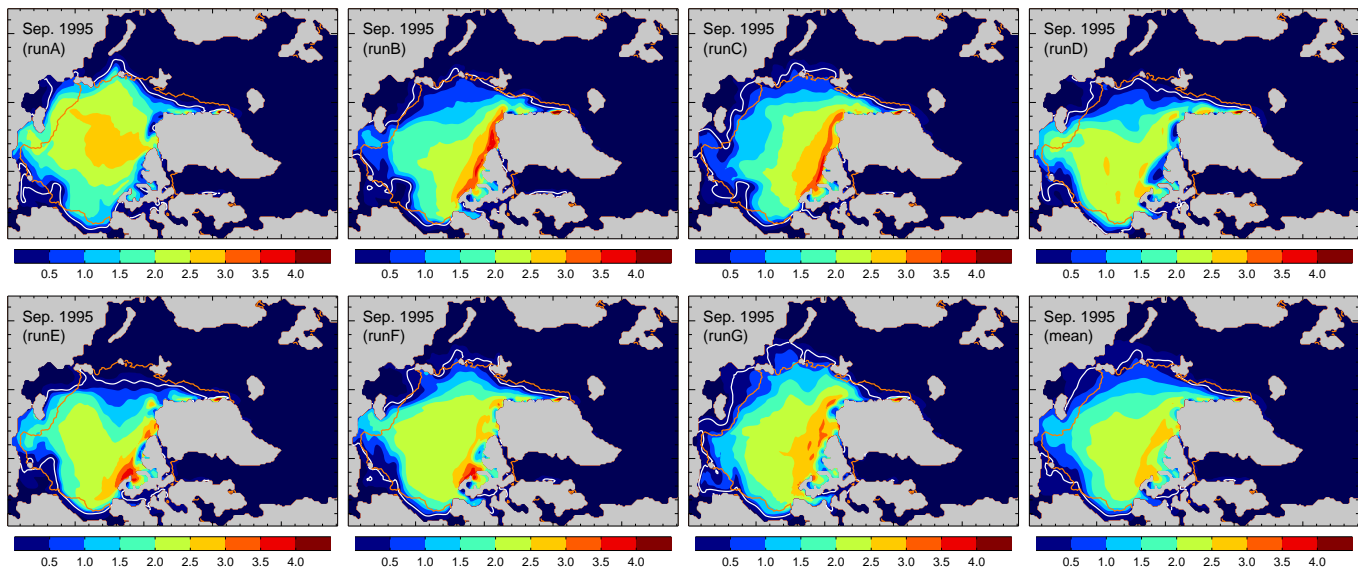

Fig. 7. Mean ice thickness in September 1995 (in meters) from the 7 ensemble members (runA to runG) and the ensemble mean (mean; bottom right). The white lines represent the simulated ice extent and the orange lines the ice extent from SSM/I satellite data. Land areas are shown in gray, and the completely ice-free ocean is shown in black.

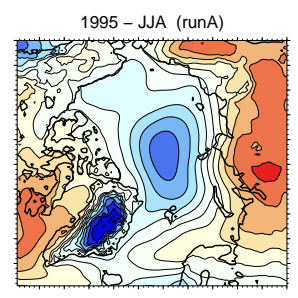

1995 - JJA (runE)

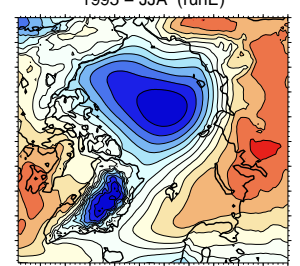

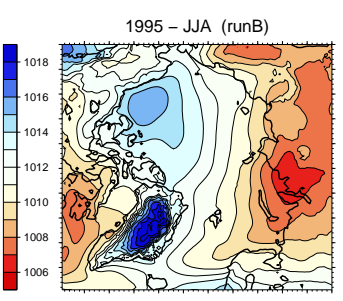

1995 - JJA (runF)

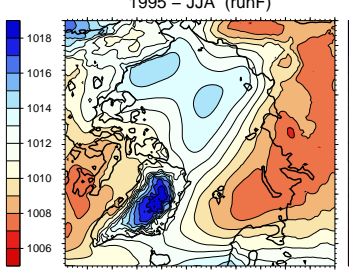

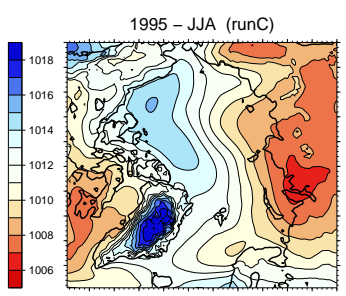

1995 - JJA (runG)

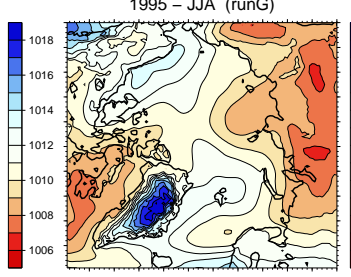

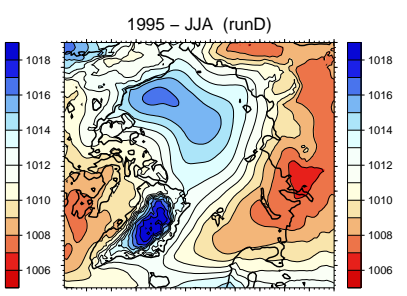

1995 - JJA (NCEP)

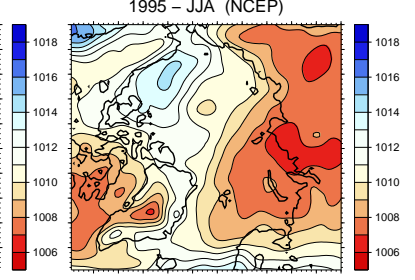

Fig. 8. Mean sea level pressure in summer 1995 (June to August; in hPa) from the 7 ensemble members (runA to runG) and NCEP/NCAR reanalysis data (bottom right).

et al., 2008; Schweiger et al., 2008; Perovich et al., 2008; Zhang et al., 2008; Ogi et al., 2008; Kauker et al., 2009; Woodgate et al., 2010). A comprehensive view of factors that, taken together, may explain the September 2007 record minimum ice extent is given by Perovich and Richter-Menge (2009). The variety of anomalous atmospheric and oceanic conditions that have probably contributed to the sea-ice loss in 2007 suggests that the realistic reproduction of such events in coupled models might represent a measure of quality for the performance of the model.

Figure 9 shows that none of the ensemble members reproduces the large ice-free area in the extended region of the Beaufort, Chukchi, East Siberian, Laptev and Kara Seas. In the Eurasian part of the Arctic, sea-ice was only observed at a short shoreline of the Taymyr Peninsula, where, in turn, most of the ensemble members do not show sea ice at all.
Differences in the ice thickness distribution of the ensemble members are also present in September 2007, but they are less pronounced than in September 1995. Despite these differences, all ensemble members basically resemble the ensemble mean (pattern correlation coefficients greater than 0.95 for both ice thickness and ice concentration). Compared to the SSM/I ice concentration, the ensemble members show pattern correlation coefficients no better than 0.71-0.77.

The observed and simulated mean sea level pressure patterns in summer 2007, however, are in rather good agreement (see Fig. 10). All ensemble members reproduce the observed pattern with low pressure over Eurasia and high pressure over the Beaufort Sea and Greenland, although runF overestimates and runG underestimates the intensity of the Beaufort Sea high, and runE and runF feature a slight shift of the Beaufort Sea high towards the central Arctic Ocean. The pattern correlation coefficients between the ensemble members 

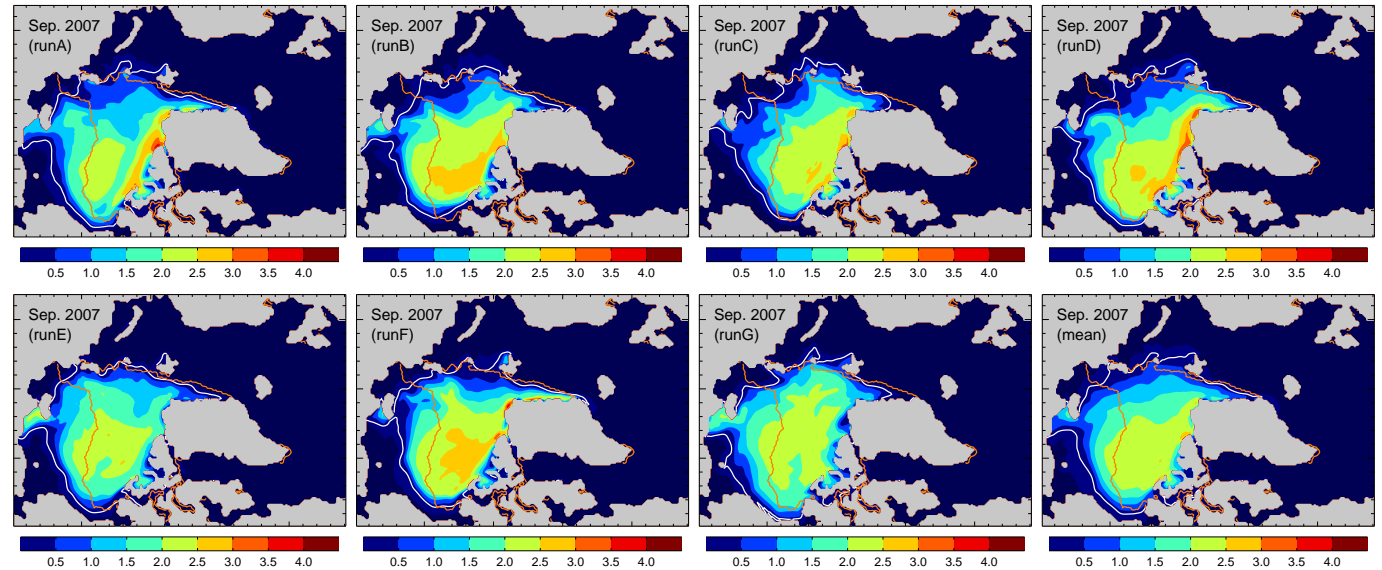

Fig. 9. As in Fig. 7, but for September 2007.

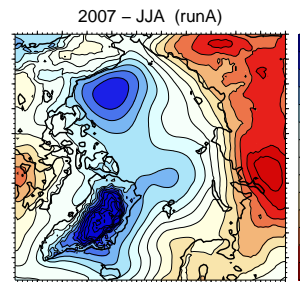

2007 - JJA (runE)
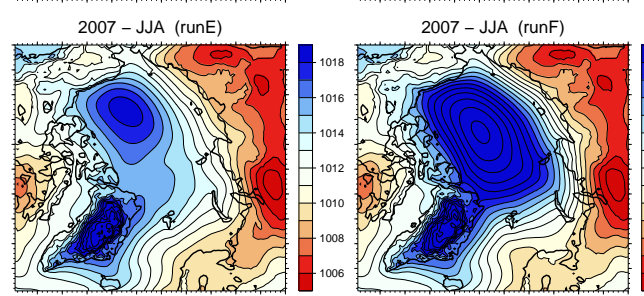

2007 - JJA (runB)

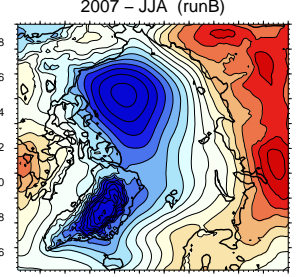

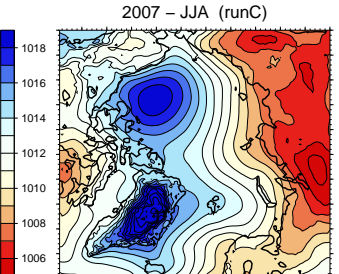

2007 - JJA (runG)

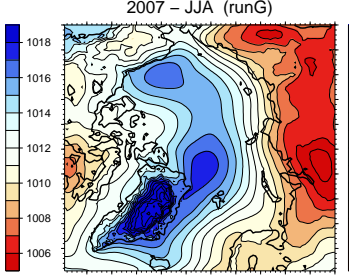

2007 - JJA (runD)

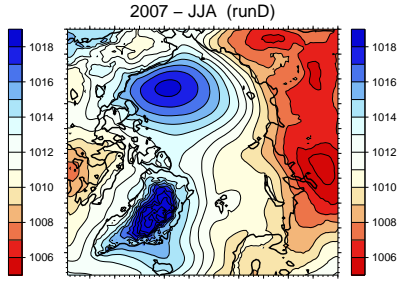

2007 - JJA (NCEP)

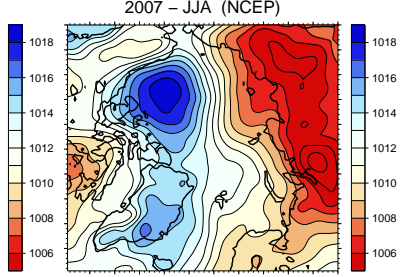

Fig. 10. As in Fig. 8, but for June to August 2007.

and the NCEP/NCAR reanalysis show relatively high values in the range between 0.81 (runF) and 0.95 (runC).

Despite the fact that all ensemble members reproduce the observed mean sea level pressure patterns in summer 2007 , none reproduces the observed September sea-ice extent. A realistic simulation of the atmospheric circulation during summer appears to be an essential but not sufficient prerequisite for a realistic simulation of the ice extent at the end of the summer. In contrast to the still relatively moderate ice retreat in 1995, atmospherically driven sea-ice drift can not be regarded as the crucial factor for the massive retreat of sea ice in 2007, in spite of a similarity to 1995 in the atmospheric circulation (positive DA) and associated sea-ice drift (strong TDS).

However, the low scatter of the ensemble members in seaice thickness and concentration in September 2007 is associated with a low scatter in the atmospheric circulation in the preceding summer months. This correlation is not specific to the year 2007 but applies as well to other years. The correlation coefficient between the time series of the domainaveraged ensemble standard deviations of the mean sea level pressure from June to August (September) and the sea-ice cover fraction in September is $0.48(0.56)$. This statistically significant but moderate correlation indicates that the internal variability of the September sea-ice cover can in large part but not completely be attributed to the internal variability of the atmospheric circulation in the preceding months.

As demonstrated in Sect. 3.3, there is a significant interannual persistence of the ice volume, including correlation with September ice extent. The state of the sea-ice cover at the beginning of the melting period might thus be another key factor for the strength of the ice retreat during the melting period. Kauker et al. (2009) showed on the basis of NAOSIM simulations that about $20 \%$ of the sea-ice anomaly in September 2007 was determined by the initial ice thickness in March, whereas the wind stress in May and June contributed to the ice anomaly with about $46 \%$. Only minor 
contributions were ascribed to the reduced cloud cover and the enhanced warm water inflow through Bering Strait.

While the minor role of the reduced cloud cover agrees with findings by Schweiger et al. (2008), the enhanced warm water inflow through Bering Strait may act as a trigger for the early onset of the ice melt and further amplification due to the ice-albedo feedback effect as noted by Woodgate et al. (2010). Since the ice-albedo feedback plays a major role in the magnitude of ice melt during summer in the coupled model (Dorn et al., 2009), it is supposed that the missing inflow of warm Pacific Waters through Bering Strait in HIRHAM-NAOSIM as well as too thick ice in the Beaufort, Chukchi, and East Siberian Seas in March 2007 (mean thickness of 2-3 m; not shown) are responsible for the missing ice retreat in the Pacific sector of the Arctic in 2007.

The reason that all ensemble members overestimate the ice thickness in the Beaufort, Chukchi, and East Siberian Seas could be due to the fact that the observed atmospheric circulation in summer 2006 is not reproduced in any of the ensemble members (pattern correlation coefficients between 0.23 and 0.70 ), accompanied by incorrect ice drift and consequently incorrect ice thickness distribution at the end of the summer 2006 and eventually wrong preconditioning of the ice cover.

\section{Summary and conclusions}

The coupled regional climate model HIRHAM-NAOSIM has been applied to identify limitations in reproducing the observed Arctic sea-ice retreat from 1948-2008. The model shows a reasonable spatial distribution of regions with thin and thick ice, but also general weaknesses in terms of a systematic overestimation of winter sea-ice extent, particularly in the Labrador Sea, and the absence of a long-term downward trend in summer sea-ice extent. The reasons for these specific weaknesses are not yet known, but they might be related to an insufficient representation of feedback processes between atmosphere, ocean, and sea ice and represent a general limitation for an exact reproduction of observed sea-ice conditions.

Ensemble simulations with HIRHAM-NAOSIM show relatively low interannual, but notable decadal variability in seaice volume. Although the decadal variability is probably triggered by long-lasting changes in the external atmospheric forcing of the model, the model's response is non-uniform among the ensemble members, particularly in periods when the ice volume increases, leading to a large scatter among the ensemble members and limited skill in reproducing high-ice years. The low interannual variability indicates a multi-year memory effect of the sea-ice pack which hampers any quick response to external fluctuations.

Variability in sea-ice extent shows a different behavior between winter and summer. Most of the variability in winter sea-ice extent is externally forced, while internal model variability plays a more prominent role during the summer. The summer sea-ice retreat is correlated with the atmospheric circulation over the Arctic Ocean. High (low) pressure over the Arctic Ocean is associated with strong (weak) sea-ice retreat. The inner-Arctic baroclinicity that arise from differential atmospheric heating between the snow-free land surface and the ice-covered Arctic Ocean during summer promotes the development of regional atmospheric circulation systems (Reed and Kunkel, 1960; Serreze and Barrett, 2008). The regional atmospheric circulation, in turn, affects the sea-ice motion and the potential for sea-ice decline and plays thus an important role in regulating annual minimum Arctic sea-ice extent (Maslanik et al., 2007; Inoue and Kikuchi, 2007; Ogi et al., 2008; Wang et al., 2009). The atmospheric circulation during the summer months might thus act as a precursor for the sea-ice conditions at the end of the summer.

Also a large part of the year-to-year change in sea ice can be attributed to the atmospheric summer circulation. This finding indicates the prime importance of inner-Arctic climate processes during the warm season for the long-term trend in sea ice. In particular the trend in sea-ice volume plays a central role, since the sea-ice volume at the beginning of the melting period represents a precondition for a realistic response to the atmospheric summer circulation and may also affect the atmospheric circulation itself, even though significant correlations between the sea-ice conditions in spring and the atmospheric circulation in summer have not been found, possibly due to nonlinear atmospheric responses to variations in the sea-ice conditions which can not be captured by means of a linear correlation analysis.

Case studies for specific years show that the model's ability to reproduce the observed summer minimum in ice extent depends on both the realistic reproduction of the atmospheric circulation during summer and the reasonable ice thickness distribution in spring, which in turn depends on the preconditioning during previous years. Given that the ratio of external to internal variability of the atmospheric variables shows its minimum value just during the summer months, when the atmospheric circulation is of particular importance, it becomes clear that the coupled model's ability to reproduce the observed summer sea-ice retreat is limited due to the intrinsic variability of the atmosphere associated with inner-Arctic feedback processes.

Despite the limited skill in reproducing realistic year-toyear variability in sea ice, the ensemble simulations provide an opportunity to quantify the inherent uncertainties in the coupled model. The impact of these model uncertainties, however, is not constant over time but depends on the given boundary conditions. There are a few years in which the Arctic atmosphere is heavily constrained by the large-scale forcing at the lateral model boundaries, as for instance in summer 2007, often accompanied by a low ensemble scatter in sea ice. This gives rise to the assumption that the model has a seasonal predictability skill only under particular large-scale atmospheric conditions. 
Acknowledgements. Financial support was provided by the Helmholtz Climate Initiative REKLIM. NCEP/NCAR reanalysis data were provided by the NOAA/OAR/ESRL PSD, Boulder, Colorado, USA, from their Web site at http://www.esrl.noaa.gov/psd/, and SSM/I sea-ice data by the National Snow and Ice Data Center (NSIDC), Boulder, Colorado, USA. Finally, we thank Rüdiger Gerdes and Frank Kauker for providing initial and forcing data for the ocean-sea ice component and two anonymous referees for their valuable comments on the discussion paper.

Edited by: D. Feltham

\section{References}

Andreas, E. L., Horst, T. W., Grachev, A. A., Persson, P. O. G., Fairall, C. W., Guest, P. S., and Jordan, R. E.: Parametrizing turbulent exchange over summer sea ice and the marginal ice zone, Q. J. Roy. Meteor. Soc., 136, 927-943, doi:10.1002/qj.618, 2010a.

Andreas, E. L., Persson, P. O. G., Grachev, A. A., Jordan, R. E., Horst, T. W., Guest, P. S., and Fairall, C. W.: Parameterizing turbulent exchange over sea ice in winter, J. Hydrometeor., 11, 87104, doi:10.1175/2009JHM1102.1, 2010b.

Bourke, R. H. and Garrett, R. P.: Sea ice thickness distribution in the Arctic Ocean, Cold Reg. Sci. Technol., 13, 259-280, 1987.

Christensen, J. H., Christensen, O. B., Lopez, P., van Meijgaard, E., and Botzet, M.: The HIRHAM4 regional atmospheric climate model, DMI Sci. Rep. 96-4, Danish Meteorological Institute, Copenhagen, Denmark, 51 pp., 1996.

Comiso, J.: DMSP SSM/I daily and monthly polar gridded bootstrap sea ice concentrations, 1987 to 2008, edited by: J. Maslanik and Stroeve, J., National Snow and Ice Data Center, Boulder, CO, digital media, 1990, updated 2009.

Comiso, J. C., Parkinson, C. L., Gersten, R., and Stock, L.: Accelerated decline in the Arctic sea ice cover, Geophys. Res. Lett., 35, L01703, doi:10.1029/2007GL031972, 2008.

Dethloff, K., Rinke, A., Lehmann, R., Christensen, J. H., Botzet, M., and Machenhauer, B.: Regional climate model of the Arctic atmosphere, J. Geophys. Res., 101, 23401-23422, 1996.

Devasthale, A., Willén, U., Karlsson, K.-G., and Jones, C. G.: Quantifying the clear-sky temperature inversion frequency and strength over the Arctic Ocean during summer and winter seasons from AIRS profiles, Atmos. Chem. Phys., 10, 5565-5572, doi:10.5194/acp-10-5565-2010, 2010.

Dorn, W., Dethloff, K., Rinke, A., Frickenhaus, S., Gerdes, R., Karcher, M., and Kauker, F.: Sensitivities and uncertainties in a coupled regional atmosphere-ocean-ice model with respect to the simulation of Arctic sea ice, J. Geophys. Res., 112, D10118, doi:10.1029/2006JD007814, 2007.

Dorn, W., Dethloff, K., and Rinke, A.: Improved simulation of feedbacks between atmosphere and sea ice over the Arctic Ocean in a coupled regional climate model, Ocean Model., 29, 103-114, doi:10.1016/j.ocemod.2009.03.010, 2009.

Döscher, R., Wyser, K., Meier, H. E. M., Qian, M., and Redler, R.: Quantifying Arctic contributions to climate predictability in a regional coupled ocean-ice-atmosphere model, Clim. Dynam., 34, 1157-1176, doi:10.1007/s00382-009-0567-y, 2010.

Eisenman, I. and Wettlaufer, J. S.: Nonlinear threshold behavior during the loss of Arctic sea ice, P. Natl. Acad. Sci. USA, 106,
28-32, doi:10.1073/pnas.0806887106, 2009.

Gerdes, R. and Köberle, C.: Comparison of Arctic sea ice thickness variability in IPCC Climate of the 20th Century experiments and in ocean-sea ice hindcasts, J. Geophys. Res., 112, C04S13, doi:10.1029/2006JC003616, 2007.

Grant, A. N., Brönnimann, S., Ewen, T., and Nagurny, A.: A new look at radiosonde data prior to 1958, J. Climate, 22, 3232-3247, doi:10.1175/2008JCLI2539.1, 2009.

Holland, M. M., Serreze, M. C., and Stroeve, J.: The sea ice mass budget of the Arctic and its future change as simulated by coupled climate models, Clim. Dynam., 34, 185-200, doi:10.1007/s00382-008-0493-4, 2010.

Holloway, G. and Sou, T.: Has Arctic sea ice rapidly thinned?, J. Climate, 15, 1691-1701, 2002.

Hunke, E. C.: Thickness sensitivities in the CICE sea ice model, Ocean Model., 34, 137-149, doi:10.1016/j.ocemod.2010.05.004, 2010.

Inoue, J. and Kikuchi, T.: Outflow of summertime Arctic sea ice observed by ice drifting buoys and its linkage with ice reduction and atmospheric circulation patterns, J. Meteorol. Soc. Jpn., 85, 881-887, doi:10.2151/jmsj.85.881, 2007.

Kalnay, E., Kanamitsu, M., Kistler, R., Collins, W., Deaven, D., Gandin, L., Iredell, M., Saha, S., White, G., Woollen, J., Zhu, Y., Leetmaa, A., Reynolds, R., Chelliah, M., Ebisuzaki, W., Higgins, W., Janowiak, J., Mo, K. C., Ropelewski, C., Wang, J., Jenne, R., and Joseph, D.: The NCEP/NCAR 40-year reanalysis project, B. Am. Meteorol. Soc., 77, 437-471, 1996.

Karcher, M. J., Gerdes, R., Kauker, F., and Köberle, C.: Arctic warming: Evolution and spreading of the 1990s warm event in the Nordic seas and the Arctic Ocean, J. Geophys. Res., 108, 3034, doi:10.1029/2001JC001265, 2003.

Kauker, F., Gerdes, R., Karcher, M., Köberle, C., and Lieser, J. L.: Variability of Arctic and North Atlantic sea ice: A combined analysis of model results and observations from 1978 to 2001, J. Geophys. Res., 108, 3182, doi:10.1029/2002JC001573, 2003.

Kauker, F., Kaminski, T., Karcher, M., Giering, R., Gerdes, R., and Voßbeck, M.: Adjoint analysis of the 2007 all time Arctic sea-ice minimum, Geophys. Res. Lett., 36, L03707, doi:10.1029/2008GL036323, 2009.

Kay, J. E., L'Ecuyer, T., Gettelman, A., Stephens, G., and O’Dell, C.: The contribution of cloud and radiation anomalies to the 2007 Arctic sea ice extent minimum, Geophys. Res. Lett., 35, L08503, doi:10.1029/2008GL033451, 2008.

Köberle, C. and Gerdes, R.: Mechanisms determining the variability of Arctic sea ice conditions and export, J. Climate, 16, 28432858, 2003.

Kwok, R. and Rothrock, D. A.: Decline in Arctic sea ice thickness from submarine and ICESat records: 1958-2008, Geophys. Res. Lett., 36, L15501, doi:10.1029/2009GL039035, 2009.

Kwok, R., Cunningham, G. F., Wensnahan, M., Rigor, I., Zwally, H. J., and Yi, D.: Thinning and volume loss of the Arctic Ocean sea ice cover: 2003-2008, J. Geophys. Res., 114, C07005, doi:10.1029/2009JC005312, 2009.

Levitus, S. and Boyer, T.: World Ocean Atlas 1994, Vol. 4: Temperature, NOAA Atlas NESDIS 4, US Gov. Printing Office, Washington DC, USA, 117 pp., 1994.

Levitus, S., Burgett, R., and Boyer, T.: World Ocean Atlas 1994, Vol. 3: Salinity, NOAA Atlas NESDIS 3, US Gov. Printing Office, Washington DC, USA, 99 pp., 1994. 
Lindsay, R. W. and Zhang, J.: The thinning of Arctic sea ice, 19882003: Have we passed a tipping point?, J. Climate, 18, 48794894, doi:10.1175/JCLI3587.1, 2005.

Maslanik, J., Drobot, S., Fowler, C., Emery, W., and Barry, R.: On the Arctic climate paradox and the continuing role of atmospheric circulation in affecting sea ice conditions, Geophys. Res. Lett., 34, L03711, doi:10.1029/2006GL028269, 2007.

Notz, D.: The future of ice sheets and sea ice: Between reversible retreat and unstoppable loss, P. Natl. Acad. Sci. USA, 106, 2059020595, doi:10.1073/pnas.0902356106, 2009.

Ogi, M. and Wallace, J. M.: Summer minimum Arctic sea ice extent and the associated summer atmospheric circulation, Geophys. Res. Lett., 34, L12705, doi:10.1029/2007GL029897, 2007.

Ogi, M., Rigor, I. G., McPhee, M. G., and Wallace, J. M.: Summer retreat of Arctic sea ice: Role of summer winds, Geophys. Res. Lett., 35, L24701, doi:10.1029/2008GL035672, 2008.

Pedersen, C. A., Roeckner, E., Lüthje, M., and Winther, J.-G.: A new sea ice albedo scheme including melt ponds for ECHAM5 general circulation model, J. Geophys. Res., 114, D08101, doi:10.1029/2008JD010440, 2009.

Perovich, D. K. and Richter-Menge, J. A.: Loss of sea ice in the Arctic, Annu. Rev. Mar. Sci., 1, 417-441, doi:10.1146/annurev.marine.010908.163805, 2009.

Perovich, D. K., Richter-Menge, J. A., Jones, K. F., and Light, B.: Sunlight, water, and ice: Extreme Arctic sea ice melt during the summer of 2007, Geophys. Res. Lett., 35, L11501, doi:10.1029/2008GL034007, 2008.

Rayner, N. A., Parker, D. E., Horton, E. B., Folland, C. K., Alexander, L. V., Rowell, D. P., Kent, E. C., and Kaplan, A.: Global analyses of sea surface temperature, sea ice, and night marine air temperature since the late nineteenth century, J. Geophys. Res., 108, 4407, doi:10.1029/2002JD002670, 2003.

Reed, R. J. and Kunkel, B. A.: The Arctic circulation in summer, J. Meteorol., 17, 489-506, 1960.

Rinke, A., Gerdes, R., Dethloff, K., Kandlbinder, T., Karcher, M., Kauker, F., Frickenhaus, S., Köberle, C., and Hiller, W.: A case study of the anomalous Arctic sea ice conditions during 1990: Insights from coupled and uncoupled regional climate model simulations, J. Geophys. Res., 108, 4275, doi:10.1029/2002JD003146, 2003.

Rothrock, D. A. and Zhang, J.: Arctic Ocean sea ice volume: What explains its recent depletion?, J. Geophys. Res., 110, C01002, doi:10.1029/2004JC002282, 2005.

Rothrock, D. A., Yu, Y., and Maykut, G. A.: Thinning of the Arctic sea-ice cover, Geophys. Res. Lett., 26, 3469-3472, 1999.

Schröder, D. and Connolley, W. M.: Impact of instantaneous sea ice removal in a coupled general circulation model, Geophys. Res. Lett., 34, L14502, doi:10.1029/2007GL030253, 2007.

Schweiger, A. J., Zhang, J., Lindsay, R. W., and Steele, M.: Did unusually sunny skies help drive the record sea ice minimum of 2007?, Geophys. Res. Lett., 35, L10503, doi:10.1029/2008GL033463, 2008.
Serreze, M. C. and Barrett, A. P.: The summer cyclone maximum over the central Arctic Ocean, J. Climate, 21, 1048-1065, doi:10.1175/2007JCLI1810.1, 2008.

Serreze, M. C., Maslanik, J. A., Scambos, T. A., Fetterer, F., Stroeve, J., Knowles, K., Fowler, C., Drobot, S., Barry, R. G., and Haran, T. M.: A record minimum arctic sea ice extent and area in 2002, Geophys. Res. Lett., 30, 1110, doi:10.1029/2002GL016406, 2003.

Serreze, M. C., Holland, M. M., and Stroeve, J.: Perspectives on the Arctic's shrinking sea-ice cover, Science, 315, 1533-1536, doi:10.1126/science.1139426, 2007.

Sorteberg, A., Furevik, T., Drange, H., and Kvamstø, N. G.: Effects of simulated natural variability on Arctic temperature projections, Geophys. Res. Lett., 32, L18708, doi:10.1029/2005GL023404, 2005.

Stevens, D. P.: The open boundary condition in the United Kingdom Fine-Resolution Antarctic Model, J. Phys. Oceanogr., 21, 1494 1499, 1991.

Stroeve, J., Markus, T., Meier, W. N., and Miller, J.: Recent changes in the Arctic melt season, Ann. Glaciol., 44, 367-374, doi:10.3189/172756406781811583, 2006.

Stroeve, J., Holland, M. M., Meier, W., Scambos, T., and Serreze, M.: Arctic sea ice decline: Faster than forecast, Geophys. Res. Lett., 34, L09501, doi:10.1029/2007GL029703, 2007.

Stroeve, J., Serreze, M., Drobot, S., Gearheard, S., Holland, M., Maslanik, J., Meier, W., and Scambos, T.: Arctic sea ice extent plummets in 2007, Eos Trans. AGU, 89, 13-14, doi:10.1029/2008EO020001, 2008.

Thorndike, A. S. and Colony, R.: Sea ice motion in response to geostrophic winds, J. Geophys. Res., 87, 5845-5852, doi:10.1029/JC087iC08p05845, 1982.

Tietsche, S., Notz, D., Jungclaus, J. H., and Marotzke, J.: Recovery mechanisms of Arctic summer sea ice, Geophys. Res. Lett., 38, L02707, doi:10.1029/2010GL045698, 2011.

Wadhams, P. and Davis, N. R.: Further evidence of ice thinning in the Arctic Ocean, Geophys. Res. Lett., 27, 3973-3975, 2000.

Wang, J., Zhang, J., Watanabe, E., Ikeda, M., Mizobata, K., Walsh, J. E., Bai, X., and Wu, B.: Is the Dipole Anomaly a major driver to record lows in Arctic summer sea ice extent?, Geophys. Res. Lett., 36, L05706, doi:10.1029/2008GL036706, 2009.

Woodgate, R. A., Weingartner, T., and Lindsay, R.: The 2007 Bering Strait oceanic heat flux and anomalous Arctic sea-ice retreat, Geophys. Res. Lett., 37, L01602, doi:10.1029/2009GL041621, 2010.

Zhang, J., Lindsay, R., Steele, M., and Schweiger, A.: What drove the dramatic retreat of arctic sea ice during summer 2007?, Geophys. Res. Lett., 35, L11505, doi:10.1029/2008GL034005, 2008. 